www.jmscr.igmpublication.org Impact Factor 5.244

Index Copernicus Value: 83.27 ISSN (e)-2347-176x ISSN (p) 2455-0450 crossref DOI: _https://dx.doi.org/10.18535/jmscr/v4i12.76

\title{
Study to Determine Relapse and Mortality Rates in Tuberculosis Cases and their Epidemiological Correlates: A Historical Cohort Study
}

\author{
Authors \\ Dr Atul Gupta, Dr Shavinder Singh, Dr Rajesh Isaac, Dr Deepshikha Kamra \\ Corresponding Author \\ Dr Atul Gupta
}

PG Resident, Dept. of Community Medicine,

Christian Medical College, Ludhiana

\begin{abstract}
Background: India is the country with the highest burden of TB. The World Health Organization (WHO) statistics for 2015 give an estimated incidence figure of 2.2 million cases of TB for India out of a global incidence of 9.6 million. The estimated TB prevalence in India for 2015 is 2.5 million.

Aims and Objectives

1. To determine the median relapse rate and to identify risk factors associated with TB relapse

2. To determine the mortality rate and its epidemiological correlates.

Methodology: All the diagnosed cases of tuberculosis over the period from Jan 2000 to Dec 2013, in the field practice areas of the Department of Community Medicine were followed up at their residences. 278 cases could be interviewed at home, and details were obtained about 14 deaths. Their history after the completion of their last course of ATT was determined, along with relevant history of disease till date using a structured questionnaire. Those who could not be located or contacted after two visits were excluded from the study. Data was entered into a Epidata Entry database and analyzed by Epidata Analysis 2.2.2 and EpiInfo 3.5.4 software.

Statistical Analysis: The percentages were used to describe relapse rates. Survival analysis was used to determine median relapse rates.

Results: 278 treated patients were available for interview. Fourteen deaths occurred among cases. Out of total 292 tuberculosis cases, 36 cases relapsed.

Out of those relapsed cases, 30 were on DOTs and 6 were on Non-DOTs regimen, but the difference was not statistically significant $(p=0.0723)$. Available data showed a high relapse rate of $12.3 \%$, exceeding the acceptable norm of less than five percent. Males were twice at the risk of relapsing as compared to females and it was statistically significant $(p=0.0099)$. Mortality in males was six times higher than females $(p=0.0029)$. Mortality in cases who were on DOTs regimen was higher as compared to cases who were on the Non-DOTs regimen, but difference was not statistically significant $(p=0.5602)$. An association was seen between chronic alcoholics and cases who relapsed for the first time $(p=0.0000)$. The association was also seen between smokers and cases who relapsed for the first time $(p=0.0000)$.

Conclusions: This retrospective cohort study revealed high relapse rates, above the recommended levels. Relapse rates were marginally higher among patients on DOTs as compared to non DOTs therapy. Mortality was six times higher in males as compared to females. Mortality rate was higher among patents on DOTs therapy as compared to non DOTs therapy. Measures to improve the compliance of DOTs therapy are urgently needed.
\end{abstract}




\section{Introduction}

The estimated tuberculosis prevalence in India for 2015 is 2.5 million ${ }^{(1)}$. It is estimated that about $40 \%$ of the Indian population is infected with TB bacteria, the vast majority of whom have latent rather than active $\mathrm{TB}{ }^{(1)}$. Tuberculosis is one of the three primary diseases of poverty along with AIDS and malaria ${ }^{(2)}$. In absolute numbers, morality due to TB has reduced from 3.3 lakhs to 2.4 lakhs annually. ${ }^{(3)}$

The registration of relapse cases are progressively increasing ${ }^{(4)}$. The relapse of TB is either due to reactivation or exogenous re-infection.

The risk factors for relapse include drug irregularity, initial drug resistance, smoking, and alcoholism. Gender and weight have been found to be significant in international studies but not in India. The Global data showed that $32 \%$ of the relapse cases are actually multidrug-resistant TB (MDR). ${ }^{(5)}$ Majority of relapses presented in the first year after 6 months of completion of treatment, and the bulk of it occurs in the first 6 months itself.

This definition, however, does not reflect the actual TB mortality rate because it includes deaths due to co-morbidities and accidents. It excludes deaths among treatment defaulters who have a high risk for mortality and presupposes that TB mortality does not occur after the completion of treatment. Case fatality rates among TB patients reported in the literature range from $12 \%$ to $44 \%$ and are not comparable because they were measured as cumulative incidence for different follow up periods. ${ }^{(7-13)}$, in 2004 total smear positive retreatment success was $70 \%$ and total smear positive retreatment death was $8 \%$.

Risk factors such as smoking, alcoholism, irregular and incomplete anti tuberculosis treatment as well as HIV infection are known to increase the mortality associated with TB. ${ }^{(7,9,}$ $10,12,14)$. RNTCP does not follow up the patients after successful completion of treatment to determine whether they relapse. Inspite of high recurrence in $\mathrm{TB}$ cases after treatment and mortality rate in TB cases, there is lack of published date on relapse rate and mortality rate. Thus, an attempt is being made in this paper to find out the median relapse rate and associated risk factors, and mortality rate and its epidemiological correlates in this historical cohort.

\section{Aims and Objectives}

1. To determine the median relapse rate and to identify risk factors associated with TB relapse

2. To determine the mortality rate and its epidemiological correlates.

\section{Methodology}

Study design is retrospective cohort. All the cases meeting the inclusion criteria in the area who were available currently were followed up. The Department of Community Medicine maintains a computerized database of all the patients who were diagnosed and/or treated for tuberculosis in the field practice areas. List of patients, treated in the area for the last 13 years, was abstracted from the database. Patients were followed up at their residences. Their history after completion of their last course of ATT was obtained, along with relevant history of disease till date and clinical examination, using a structured questionnaire. Inclusion Criteria: All diagnosed cases of people who suffered from tuberculosis over the period Jan 2000 to Dec 2013, who underwent anti tuberculosis treatment and whose treatment and outcome details were still available and/or present in the field practice areas. Those who could not be located or contacted were excluded.

Relapse is defined as a TB patient who was declared cured or treatment completed by a physician, but who reports back to the health service and is now found to be sputum smear positive.

Mortality: WHO defines TB mortality as the number of TB cases dying during treatment, regardless of the cause. (6) This definition, however, does not reflect the actual TB mortality rate because it includes deaths due to comorbidities and accidents, excludes deaths among treatment defaulters who have a high risk for 
mortality and presupposes that TB mortality does not occur after the completion of treatment. Mortality from TB is defined as the number of deaths caused by TB in HIV-negative people, according to the latest revision of the International classification of diseases (ICD-10). Data was entered using classical Epidata Entry software and data analysis was performed using Epidata analysis Version 2.2.2 and EpiInfo 3.5.4 software. Statistical Analysis : The proportions were used to determine relapse rates and mortality rates. Odds ratios were calculated to quantify risk factors.

\section{Results}

Out of the total 292 tuberculosis cases, 206 $(70.5 \%)$ were pulmonary and $86(29.5 \%)$ extra pulmonary cases. $206(70.5 \%)$ were treated DOTs regimen, of which 187 were on Category-I (93.6\% completed treatment), 19 were on Cat-III $(89.5 \%$ completed treatment) while 86 were on NonDOTs regimen (93\% completed treatment).

Out of $36(12.3 \%)$ cases relapsed, 86.1 percent were pulmonary and 13.9 percent extra- pulmonary tuberculosis. 33 patients were on DOTs regimen and 3 on Non-DOTs regimen. Thirty, out of 36 relapsed cases, completed their treatment. Two cases relapsed for second time.

Overall median relapse rate per 100 person years was found to be 2.86. Cases on DOTs regimen had twice the risk of relapsing as compared to Non-DOTs regimen but the difference was not statistical significant. The median relapse rate was found to be more than twice among males as compared to females and the difference was statistically significant. The median relapse rate was found to be three times higher among patients receiving DOTs regime as compared to those on Non-DOTs regimens. Out of 36 relapsed cases, $15(41.7 \%)$ were smokers as compared to non smokers $21(58.3 \%)$ and the difference was statistically significant $(\mathrm{p}=0.000)$. Chronic alcoholics had five times the risk of relapsing as compared to non-alcoholics and it was statistically significant. No association was seen between relapse and diagnosed diabetic mellitus.

Table 1. Mortality rates among different age groups (age at first diagnosis), gender and ATT treatment regimens groups

\begin{tabular}{|c|c|c|c|c|c|}
\hline & $\begin{array}{l}\text { Tuberculosis } \\
\text { Cases }\end{array}$ & Morality rate $(\%)$ & Odds ratio & Chi square & $\overline{p \text {-value }}$ \\
\hline \multicolumn{6}{|c|}{ Age group(yrs) } \\
\hline $0-9$ & 13 & 0 & & \multirow[t]{7}{*}{1.51} & \multirow[t]{7}{*}{0.22} \\
\hline $10-19$ & 50 & 0 & & & \\
\hline $20-29$ & 71 & 0 & & & \\
\hline $30-39$ & 50 & $2(4.0)$ & 1 & & \\
\hline $40-49$ & 41 & $5(12.2)$ & 3.3 & & \\
\hline $50-59$ & 33 & $2(6.1)$ & 1.5 & & \\
\hline$\geq 60$ & 34 & $5(15.2)$ & 4.1 & & \\
\hline \multicolumn{6}{|l|}{ Gender } \\
\hline Male & 136 & $12(8.8)$ & 1 & \multirow[t]{2}{*}{10.74} & \multirow[t]{2}{*}{0.001} \\
\hline Female & 156 & $2(1.3)$ & 0.13 & & \\
\hline \multicolumn{5}{|c|}{ Type of treatment } & \\
\hline Dots & 206 & $9(4.3)$ & 1 & \multirow[t]{2}{*}{0.05} & \multirow[t]{2}{*}{0.82} \\
\hline Non-dots & 86 & $5(5.9)$ & 1.4 & & \\
\hline
\end{tabular}

Mortality was seen above the age group of 30 years with a fluctuation in the age group of 50-59 years. Overall mortality was 4.8 percent. Mortality rate in males was six times higher as compared to females and it was statistically significant. Mortality was seen more in cases who were on Non-DOTs regimen than DOTs regimen but it was not statistically significant. 
Table 2. Relapse rates among different age groups (age at first diagnosis), gender, ATT treatment regimens group, smokers and chronic alcoholics.

\begin{tabular}{|c|c|c|c|c|c|}
\hline & TB Cases & Relapse rate $(\%)$ & Odds ratio & Chi square & p-value \\
\hline \multicolumn{6}{|c|}{ Age group (yrs) } \\
\hline $0-9$ & 13 & 0 & & \multirow[t]{7}{*}{0.25} & \multirow[t]{7}{*}{0.61} \\
\hline $10-19$ & 50 & $4(08)$ & 01 & & \\
\hline $20-29$ & 71 & $13(18)$ & 2.6 & & \\
\hline $30-39$ & 50 & $2(4.0)$ & 0.5 & & \\
\hline $40-49$ & 41 & $6(14.6)$ & 1.9 & & \\
\hline $50-59$ & 33 & $8(24.2)$ & 3.7 & & \\
\hline$\geq 60$ & 34 & $3(8.8)$ & 1.1 & & \\
\hline \multicolumn{6}{|l|}{ Gender } \\
\hline Male & 136 & 24 (17.6) & 1 & \multirow[t]{2}{*}{7.59} & \multirow[t]{2}{*}{0.0058} \\
\hline Female & 156 & $12(7.7)$ & 0.4 & & \\
\hline \multicolumn{6}{|c|}{ Type of treatment } \\
\hline DOTs & 206 & $30(15.7)$ & 1 & \multirow[t]{2}{*}{3.96} & \multirow[t]{2}{*}{0.046} \\
\hline Non DOTs & 86 & $6(3.6)$ & 0.4 & & \\
\hline \multicolumn{6}{|l|}{ Smoking } \\
\hline Yes & 28 & 15 (53.6) & 1 & \multirow[t]{2}{*}{52.87} & \multirow[t]{2}{*}{0.00} \\
\hline No & 264 & $21(7.9)$ & 0.1 & & \\
\hline \multicolumn{6}{|l|}{ Alcohol } \\
\hline Yes & 31 & $14(45.2)$ & 1 & \multirow[t]{2}{*}{37.94} & \multirow[t]{2}{*}{0.00} \\
\hline No & 261 & $22(8.4)$ & 0.1 & & \\
\hline
\end{tabular}

\section{Discussion}

There is paucity of retrospective cohort studies in the published studies.

Tuberculosis mortality and associated risk factors:

Tuberculosis mortality and Gender - In present study, mortality in males (8.8 percent) was six times higher than in the females (1.3 percent) during the course of treatment. Didilescu $\mathrm{C}$ et al shows standardized mortality rate for males in Romania, in 2009, was 6.5 times higher than in women. ${ }^{(15)}$

Uchimura et al showed that males in most risk groups had higher mortality than females; the mortality of all TB cases in all age groups for both males and females were 3.6, 24 times higher than the general population ${ }^{(16)}$.

Tuberculosis mortality and Smoking: In current study, smoking was associated with relapse. Out of 36 relapsed cases, 15 were smokers (41.7 percent) as compared to non smokers which was statistically significant $(p=0.000)$. Thomas A et al reported that smoking was associated with relapse (OR 3.1; 95\% CI 1.6-6.0). Almost 68 percent of men were smokers and were thrice as likely to relapse as those who did not smoke ${ }^{(17)}$. Batista JL et al studied the association between smoking and relapse and concluded that smoking increases the risk of relapse after successful tuberculosis treatment (OR 2.53, 95\% CI: 1.23-5.21). (18) Kolappan $\mathrm{C}$ et al conducted a community-based cross sectional survey from June 2001 to December 2003. A total of 93,945 individuals aged 15 years selected from a random sample of villages in a district from South India and data on exposure to tobacco smoking were collected from the male population only. All females were considered non-smokers. A total of 429 bacteriological positive cases was detected during the survey. The adjusted odds ratio for smoking was 2.1 (95\%CI: 1.7-2.7), it was concluded that risk factor such as smoking is associated with pulmonary TB ${ }^{(19)}$.

Relapse among Tuberculosis cases: According to current study, the percentage relapse among tuberculosis cases was 12.24 percent. Joseph et al reported relapse of 9.27 percent as a worst case scenario for full target population. ${ }^{(20)}$ 
Tuberculosis mortality and chronic alcoholism:

In the present study, chronic alcoholism was associated with relapse (45.2 percent) and is statistically significant $(\mathrm{p}=0.0000)$.

Association between gender and relapse among tuberculosis case: In current Study, males had twice the risk of relapsing as compared to females and it was statistically significant $(\mathrm{p}=0.0088)$, $(\mathrm{OR}=2.61,95 \%$ CI: 1.25-5.44) Soomro JA, Qazi HA showed relapse was higher in males $(70 \%)$ than female $(29.9 \%) .{ }^{(21)}$ Gustafson et al has shown that risk factors for failure, default, or early relapse after initial treatment included male gender $(\mathrm{OR}=2.29,95 \%$ CI $1.10-4.77){ }^{(22)}$ Srinath $\mathrm{S}$ et al conducted a study of 1009 patient records of 'retreatment and others'. All patients were treated with the RNTCP intermittent (thriceweekly) retreatment regimen. Eighty percent was successfully treated (cured plus treatment completed). Successful outcomes were higher in females $(84 \%)$. ${ }^{(23)}$

\section{Conclusion}

Relapse rates were twice among males as compared to females. Relapse rate was four times higher among patients treated with DOTs as compared to Non DOTs cases and the difference was marginally significant. Relapse rates can be reduced by ensuring that patients take their treatment regularly and are counseled effectively to stop smoking and alcohol intake. Mortality rate in males was six times higher as compared to females and it was statistically significant. Mortality was higher in cases, who were on NonDOTs than DOTs regimen but the difference was not statistically significant.

\section{Recommendations - Reinforcing the} implementation of the DOTS strategy and strengthening the anti-smoking campaigns are important actions. All category II PTB patients, given the high prevalence of MDR-TB, should be screened for MDR-TB using the novel diagnostic test.

Educational programs focusing on reducing stigma, improving good perception, correcting the wrong ones that people have learnt about the disease, needs to be implemented.

\section{Bibliography}

1. "Global Tuberculosis Control 2015, WHO, Geneva, 2015 www.who.int/tb/publications/global_report/

2. Nobel Foundation. The Nobel Prize in Physiology or Medicine 1905. [Cited 2010 Sep 10];Available from: URL:http://de.wikipedia.org/.../Simple:No bel_Prize_in_Physiology_or_Medicine.

3. Govt. of India. TB India 2011, RNTCP status report, Central TB Division. New Delhi: Ministry of Health and Family Welfare, Govt. of India; 2011.

4. T. Santha, R. Garg, T. R. Frieden, V. Chandrasekaran, R. Subramani, P. G. Gopi, N.Selvakumar, S. Ganapathy, N Charles, J. Rajamma, P.R Narayanan. Risk factors associated with default, failure and death among tuberculosis patients treated in a DOTS Programme in Tiruvallur District, South India, 2000. International Journal of Tuberculosis and Lung Disease, 2002; 6(9): 780-788. Co

5. World Health Organization. Treatment of tuberculosis guidelines. 4th ed. [accessed on May 27, 2012]. WHO/HTM/TB/2009.420. Available from:http://whqlibdoc.who.int/publications /2010/9789241547833_eng.pdfSimilar

6. Murray CJL, Lopez AD, editors. The global burden of disease. Cambridge: Harvard University Press; 1996

7. Cullinan P, Meredith SK. Deaths in adults with notified pulmonary Tuberculosis 1983-5. Thorax 1991;46:347-350.

8. Glynn JR, Warndorff DK, Fine PEM, Munthali MM, Sichone W, Ponnighaus M. Measurement and determinants of tuberculosis outcome in Karonga District, Malawi.Bull World HealthOrgan 1998;76:295-305

9. Pablos-Mendez A, Sterling TR, Frieden TR. Therelationship between delayed or 
incomplete treatment and all-cause mortality in patients with tuberculosis. JAMA 1996;276:1223-1228.

10. Walpola HC, Siskind V, Patel AM, Konstantions A, Derhy P. Tuberculosisrelated deaths in Queensland Australia, 1989-1998: characteristics and risk factors. Int $\mathbf{J}$ Tuberc and Lung Dis 2003;7:742-750.

11. National Tuberculosis Institute, Bangalore. Tuberculosis in a rural population of South India five-year epidemiological study. Bull World Health Organ 1974;51:473-488.

12. Gajalaxmi V, Peto R, Santhana krishnakanaka T, Jha P. Smoking and mortality from tuberculosis and other diseases in India: retrospective study of 43000 adult male deaths and 35000 controls. Lancet 2003;362:507-515.

13. Datta M, Radhamani MP, Selvaraj R, Paramasivan CN, Gopalan BN, Sudeendra $\mathrm{CR}$, et al. Critical assessment of smear positive pulmonary tuberculosis patients after chemotherapy under the district tuberculosis programme. Tuber Lung Dis 1993;74:180-186.

14. WHO Tuberculosis Programme. Frame work for effective tuberculosis control. Geneva, Switzerland: World Health Organization; 1994. WHO document WHO/TB/94. p. 179

15. Didilescu C, Popescu G, Cioran N, Cocei H. [Mortality of tuberculosis in Romania, a marker for severity of the endemic]. Pneumol Buchar Rom. 2012 Sep; 61 (3): 150-2

16. Characteristics and treatment outcomes of tuberculosis cases by risk groups, Japan, 2007-2010 | Uchimura | Western Pacific Surveillance and Response [Internet]. [Cited 2016 Jun 5]. Available from: http://ojs.wpro.who.int/ojs/index.php/wpsa r/article/view/186/237

17. Thomas A, Gopi PG, Santha T, Chandrasekaran V, Subramani R, Selvakumar N, et al. Predictors of relapse among pulmonary tuberculosis patients treated in a DOTS programme in South India. Int $\mathbf{J}$ Tuberc Lung Dis Off J Int Union Tuberc Lung Dis. 2005 May; 9 (5): 556-61.

18. Batista JL, Albuquerque MFPM, Ximenes RAA, Rodrigues LC. Smoking increases the risk of relapse after successful tuberculosis treatment. International Journal of Epidemiology 2008;37:841-851

19. Kolappan C, Gopi PG, Subramani R, Narayanan PR. Selected biological and behavioral risk factors associated with pulmonary tuberculosis. Int. Jour. Tuberc Lung Dis. 2007;11(9):999-1003.

20. Joseph MR, Thomas RA, Nair S, Balakrishnan S, Jayasankar S. Directly observed treatment short course for tuberculosis. What happens to them in the long term? Indian J Tuberc. 2015 Jan; 62 (1): $29-35$

21. Soomro JA., Qazi HA., Factors Associated with relapsed tuberculosis in males and females: a comparative study. Tanaffos. 2009; 8, 22-27

22. Gustafson P., Gomes V. F., Vieira C. S., et al. Tuberculosis in Bissau: incidence and risk factors in an urban community in subSaharan Africa. International Journal of Epidemiology. 2004;33(1):163-172. doi: 10.1093/ije/dyh026. [PubMed].

23. Srinath S, Sharath B, Santosha K, Chadha SS, Roopa S, Chander $\mathrm{K}$, et al. Tuberculosis "retreatment others": profile and treatment outcomes in the state of Andhra Pradesh, India. Int J Tuberc Lung Dis Off J Int Union Tuberc Lung Dis. 2011 Jan; 15 (1): 105-9. 